\title{
The Relationship Between Sleep Disorders During Pregnancy and Miscarriage
}

\author{
Elham Alihosseini, ${ }^{1}$ Shanaz Najar,, ${ }^{2,}$ and Mohammad Hossein Haghighizadeh ${ }^{3}$ \\ ${ }^{1}$ Department of Nursing and Midwifery, Ahvaz Jundishapur University of Medical Sciences, Ahvaz, Iran \\ ${ }^{2}$ Reproductive Health Promotion Research Center, Department of Midwifery, Ahvaz Jundishapur University of Medical Sciences, Ahvaz, Iran \\ ${ }^{3}$ Department of Statistics and Epidemiology, Ahvaz Jundishapur University of Medical Sciences, Ahvaz, Iran \\ Corresponding author: Shanaz Najar, Reproductive Health Promotion Research Center, Department of Midwifery, Ahvaz Jundishapur University of Medical Sciences, Ahvaz, \\ Iran. Tel: +98-9166129001, E-mail: E. Najarshanaz@yahoo.com
}

Received 2016 October 01; Revised 2017 February 27; Accepted 2017 March 27.

\begin{abstract}
Background: Sleep disorder is one of the most common complaints of pregnancy that can lead to maternal and fetal complications. Objectives: The main purpose of this study is to investigate the correlation between sleep disorders of pregnancy and abortion. Methods: This study is conducted using a case-control method on 218 women in the age range of 18 - 35 years old with singletonpregnancy passing their first or second pregnancy in Ahvaz, Iran. Continuous sampling was conducted on the basis of characteristics of the research unit. The case group $(n=109)$ included women hospitalized because of an abortion, and the control group ( $n$ $=109$ ) consists of pregnant women above 22 weeks, who were referred to healthcare centers to get pregnancy cares. The data collection was done using a demographic questionnaire and pittsburgh sleep quality index (PSQI). Data analysis was performed using SPSS-22 and t-test for quantitative variables and Chi-Square for qualitative variables.

Results: Obtained results from the study showed that there is a significant relationship between abortion and sleep duration $(\mathrm{P}=$ $0.000)$, subjective sleep quality $(\mathrm{P}=0.000)$, sleep latency $(\mathrm{P}=0.000)$, habitual sleep efficiency $(\mathrm{P}=0.000)$, sleep disturbances $(\mathrm{P}=$ $0.000)$, daytime dysfunction $(\mathrm{P}=0.000)$, and total valued of sleep disorder $(\mathrm{P}=0.000)$. However, the correlation was insignificant in case of use of sleeping medication $(\mathrm{P}=0.233)$.

Conclusions: According to the obtained results, there is a significant correlation between sleep disorder and abortion. Therefore, training sleep health and suitable consultations during pregnancy would be effective in field of preventing abortion and with the aim of achieving to safe pregnancy.
\end{abstract}

Keywords: Dyssomnias, Pregnancy, Aborted Fetus

\section{Background}

Although the level of need to sleep varies according to age and sex of individuals, National Sleep Foundation recommends 7 to 8 hours sleep per day for adults (1). In Maslow's Hierarchy of Needs, sleep is one of the most fundamental needs of a human that can lead to reduction of stress, enhancement of power, and concentration of daily activities in addition to preserve mental and physical health (2).

Chronic sleep disorder refers to cases were patients complain about one or more problem such as Insomnia, frequent waking during the night, increased sleepiness during the day, or unusual movements and sensations during sleep (3). At the human societies, sleep disorder has a prevalence of about 30\% (4). According to the investigations, more than 6 million people in Iran suffer from sleep disorders (5). On the other hand, sleep disorders in women is 2 times more than men (6). In 2004, a general surgeon in America found that sleep disorders, sleep deprivation, and sleepiness affects as great as 70 million Americans, result- ing in an annual loss of $\$ 16$ billion dollars for health care costs and $\$ 50$ billion dollars for loss of productivity (7).

Factors such as weight gain, increased age, job, and physical and mental health can interfere in occurrence of sleep disorders (8). One of the most common factors affecting sleep disorders that a few studies are conducted about it is pregnancy (6). Such a disorder can be due to physiological, hormonal, vascular, and metabolic changes. $49 \%$ of women suffer from insomnia during pregnancy (5). Recently, the National Sleep Foundation reported in a poll that more than $71 \%$ of women, reported that their sleep during pregnancy is different from any other time, however, about which aspects of their sleep had changed, any explanation hadn't been reported (1). In general, about 2 thirds of pregnant women have abnormal sleep pattern (9). Experimental studies show that $25 \%$ of women in the first trimester of pregnancy and about $75 \%$ in the third quarter significantly suffer from sleep disorders (9, 10). While growth of sleep disorders during pregnancy has been proven (10-12), our current knowledge severely is based on a handful of reports (13). 
Lack of sleep is a known impact in hormonal cycles of women including estrogen, progesterone, Luteinizing hormone, follicle stimulating hormone, and prolactin. Hence, sleep disorder may have negative effects on the health of women, especially during pregnancy (14). Sleep interruption has negative effects on pulsatile release of LH. As a result, it can affect pregnancy (15). Changes in sleeping pattern like those with job shifts can result in irregular menstruation and intensification of fertility problems (16). Among women with sleep-disordered breathing (SDB), those with obstructive sleep apnea (OSA) experience intermittent hypoxemia, which can lead to inflammation, oxidative stress and excess sympathetic activation. The increased oxidative stress may also contribute to endothelial dysfunction and the presence of increased proinflammatory cytokines such as C-reactive protein (CRP), interleukin-6 (IL-6), and tumor necrosis factor (TNF) $\alpha$, all of which have been linked to adverse pregnancy outcomes (17). Moreover, the studies have shown that chronic deprivation of sleeping can enhance immune response and level of inflammatory factors such as interleukin (IL-1), IL-2, IL-6, IL-10, INF- $\alpha$ and C-reactive protein (CRP) considerably (1822). OSA with reduction of leptin level can lead to disorder in blood sugar control. All mentioned factors are related to gestational diabetes, preeclampsia and finally, termination of pregnancy $(17,23-26)$.

Abortion is a common problem during pregnancy and about $12 \%$ of pregnancies would be ultimately ended by abortion. However, the voluntary cases are not counted in these statistics (27). The Centers for Disease Control (CDC) in the U.S and world health organization (WHO) have defined abortion as termination of pregnancy before 20 weeks of birth of a child with weight below $500 \mathrm{gr}(23,28)$. More than $80 \%$ of abortions in the first 12 months are resulted from accidents and mostly as a result of chromosomal abnormalities (29). By 2011, in 49 districts of states of Colombia, New York, California, Maryland, and New Hampshire, 730,322 abortions are reported to $\mathrm{CDC}$, so that the level of abortion in these regions is equal to 13.9 per 1000 women in the age range of 15 - 44 years old and 219 abortions per 1000 healthy childbirths (30). In Nigeria, $10 \%$ of women have experienced 1 abortion during their life, so that 760,000 abortions are reported in this country per year (31). According to statistics presented by the ministry of health and medical education in Iran, annually 80 000 abortions (200 cases per day) are being occurred (32). Prevalence of abortion in Qom province by 2001 has been equal to $28.8 \%$ and this value has been about 65 cases per 1000 patients during 1002 - 2001 in Kermanshah Province $(33,34)$.

The main immunologic factors result in abortion include high level of cytokines, interferon (INF), TNF- $\alpha$, IL-1,
IL-2, IL-3, IL-10 and C-reactive Protein (CRP), natural killer cell (NK), Anti-Phospholipid Antibodies (APA), antinuclear antibodies (ANA) or low level of IL-4, IL-5, IL-15, and Luteal insufficiency. In fact, during a normal pregnancy, level of T-helper cells (TH2) is higher than TH1 in endometrial and decidua. Increase in ration of TH1 cells (production of cytokines IL-2, TNF and INF- $\gamma$ that are harmful for fetus) compared to cells (production of cytokines of Il-4, IL-5, IL-15 and LIF that are useful for fetus) can increase cytokine against fetus or lack of suitable stimulation of proliferation and differentiation of trophoblast and can finally lead to lack of implantation and abortion (35).

In a study conducted by Baker et al. (2010), with the aim of investigating boarding rhythm of sleep and menstruation, the results showed that change in boarding rhythm of sleep and hormonal secretion in menstruation cycle can affect stability of internal space of uterus for implantation and growth of fetus (16).

Recent studies have demonstrated that Apnea Hyponea index (AHI) and body mass index (BMI) are significant predictor factors for number of the abortions. In other words, obtained data shows the correlation between sleep-disordered breathing (SDB) and abortion (36). Moreover, Louis et al. showed that obstructive sleep apnea during pregnancy can lead to risk of preeclampsia, preterm birth, and material complications (37). It has been demonstrated in studies that sleep disorders symptoms are more prevalent during pregnancy and the symptoms can be along with increased probability of preterm birth, diabetes, preeclampsia, and low Apgar score (38).

According to the need for further studies in field of sleep disorders during pregnancy and its impact on result of pregnancy and high prevalence of spontaneous abortion, necessity of paying attention to correlation between pregnancy sleep disorders and abortion is tangible. Hence, this study has been conducted with the aim of investigating the correlation between sleep disorders during pregnancy and abortion.

The main purpose of this study is to investigate the correlation between sleep disorders during pregnancy and abortion.

\section{Methods}

This study is a case-control research. Sampling done in the Gyn ward in teaching hospital, specialty, governmental and referral Imam Khomeini, Razi and selected health center of Ahvaz. The study was approved by the ethics committee of Ahvaz Jondishapur University of Medical Sciences in February 2016 (IR.AJUMS.REC.1394.642). After getting permission from the hospital and selected healthcare centers 
and gave explanation of the purposes of the study to authorities and research units, sampling was performed continuously. Sample size is equal to 218 people divided to case and control groups. The inclusion conditions included singleton pregnancy, first and second pregnancy, age of 18 30 years old and BMI of 19.8 - 25 and exclusion criteria included chronic diseases of mother (Diabetes mellitus, hypertension, kidney disease and cardiovascular disease), addiction to drugs, alcohol and smoking and having experience of abortion. Case group $(n=109)$ included all women with inclusion conditions who were hospitalized in hospital because of abortion and control group $(n=109)$ included pregnant women with pregnancy over 22 weeks referred to healthcare centers to get pregnancy care. The 2 groups were matched for age, parity, and BMI.

After sufficient explanation of the procedure to the patients and ensuring them in terms of secrecy of private information, written consent was received. The author fulfilled demographic information scale and PSQI scale for each sample according to their statements. Demographic scale included personal information such as age, education level, and job, number of gravidity, and number of parity, history of infertility, history of abortion, family income level, and BMI. PSQI scale included 7 domains including sleep duration, sleep latency, subjective sleep quality, habitual sleeping medication and daytime dysfunction, which were investigated respectively. The score of each component is from 0 (without disorder) to 3 (severe disorder). The total score of each domain is obtained based on addition of scores of the domain. The range of scores was to 0 - 21 and the total score of 5 and higher scores indicated considerable sleep disorder. Philips et al. confirm validity and reliability of PSQI by 2001 (8). In Iran, the validity and reliability of the scale are tested by another study (2007) and proved that the scale has reliability to $83 \%$ and validity to $85 \%$ (3). Data analysis is done using SPSS-22 and t-test for quantitative variables and chi-square for qualitative variables.

\section{Results}

In this study, 109 women were placed in the case group and 109 women in the control group. Obtained results from the study showed that the mean age range in the case group is equal to $28.89(\mathrm{SD}=5.35)$ and in control group, the value is equal to $28.96(\mathrm{SD}=4.86)$. Details of demographic and gynecology information in the studied groups are respectively presented in Tables 1 and 2 .

Obtained results show that there is significant correlation between abortion and sleep duration $(\mathrm{P}=0.000)$ subjective sleep quality $(P=0.000)$, sleep latency $(P=0.000)$, habitual sleep efficiency $(\mathrm{P}=0.000)$, sleep disturbances $(\mathrm{P}$
$=0.000)$, daytime dysfunction $(\mathrm{P}=0.000)$, and total valued of sleep disorder $(\mathrm{P}=0.000)$. However, the correlation was insignificant in case of use of sleeping medication $(\mathrm{P}=$ 0.233 ) (Table 3 ).

\section{Discussion}

According to the obtained results from this study, the mean age range of women in case group is equal to 28.89 \pm 5.35 and it is equal to $28.96 \pm 4.86$ in the control group. In the study of Khlil, this factor was in a significant correlation with abortion $(\mathrm{P}<0.001)(39)$. Espiritu has found in a study that sufficient sleep is decreased with the increase in age (40). Therefore, people in low mean age range have been selected for the study. Aaron has introduced weight gain of mother as a disrupting factor affecting sleep quality (41). On the other hand, Nasser et al. have also introduced high BMI as an important factor affecting abortion that should be controlled (42). Therefore, in this study, all samples were in normal weight range in terms of BMI. According to other effective factors such as age of spouse and number of previous deliveries, the 2 groups were synchronized.

In this study, significant correlation is obtained between sleep insufficiency and abortion $(P=0.000)$ and Obrien has also found that there is a significant correlation between sleep insufficiency and stillbirth (43). According to PSQI, habitual snoring and breathing disorders can result in sleep disorder in individuals, and according to Obrien, the breathing disorder can lead to stillbirth. In this study, significant correlation was observed between sleep disorder and abortion $(\mathrm{P}=0.000)(43)$.

In recent years, sleep duration has been reduced sharply, which it is associated with increased prevalence of obesity. Chronic sleep restriction, such as self-imposed short sleep duration, through impact on neuroendocrine functions plays a central role in pathophysiology of overweight and obesity. Chronic sleep disorders including short sleep duration and sleep fragmentation independent of weight and poor glycemic control is a major factor in determining metabolic health $(43,44)$. Pathogenesis process of illness is most likely due to abnormal implantation and abnormal development vessels of the placenta in early periods of pregnancy that this process leads to oxidative stress and inflammation and followed by the release of antiangiogenic agents and widespread disruption of endothelial function. In general, sleep disorders, including poor sleep quality in early pregnancy will have a negative impact on implantation (45).

Maternal sleep disorders, as an important factor for adverse pregnancy outcomes, are emerging (43). Low sleep quality, reduced sleep duration, and continuity and sleep 


\begin{tabular}{|c|c|c|c|}
\hline Variable & Case, $\mathrm{N}=109$ & Control, $\mathrm{N}=109$ & P Value \\
\hline Age, $y$ & $28.89 \pm 5.35$ & $28.96 \pm 4.86$ & 0.9 \\
\hline Age of husband, $y$ & $34.07 \pm 6.36$ & $32.92 \pm 6.84$ & 0.1 \\
\hline BMI & $22.16 \pm 1.36$ & $21.87 \pm 1.56$ & 0.1 \\
\hline Family income, Rials ${ }^{a}$ & $14431192 \pm 8738343$ & $14899082 \pm 8854738$ & 0.6 \\
\hline Education & & & 0.08 \\
\hline High school & $40(36.7)$ & $32(29.4)$ & \\
\hline Diploma & $44(40.4)$ & $37(33.9)$ & \\
\hline University education & $25(22.9)$ & $40(36.7)$ & \\
\hline Job & & & 0.06 \\
\hline Working & $16(14.7)$ & $27(24.8)$ & \\
\hline Housewife & $93(85.3)$ & $82(75.2)$ & \\
\hline
\end{tabular}

Abbreviation: BMI, Body Mass Index.

${ }^{a}$ One U.S. dollar is equal to $34,000-35,000$ Rials at the time of data collection.

Table 2. Obstetric Information of Studied Groups

\begin{tabular}{|cccc}
\hline Variable & Case, $\mathbf{N}=\mathbf{1 0 9}$ & Control, N=109 & P Value \\
\hline Contraceptive method & & & 0.1 \\
\hline Tab & $34(31.2)$ & $22(20.2)$ & \\
\hline AMP/IUD & $4(3.7)$ & $5(4.6)$ & \\
\hline Candom & $13(11.9)$ & $23(21.1)$ & \\
\hline withdrawal & $48(44)$ & $54(49.5)$ & 0.7 \\
\hline Unprotected & $10(9.2)$ & $5(4.6)$ & \\
\hline History of infertility & & & \\
\hline Yes & $4(3.7)$ & $3(2.8)$ & 0.4 \\
\hline No & $105(96.3)$ & $106(97.2)$ & 0.4 \\
\hline Parity & $0.72 \pm 0.5$ & $0.77 \pm 0.44$ & \\
\hline Number of stillbirths & $1.2 \pm 0.44$ & $1 \pm 0$ & \\
\hline
\end{tabular}

disordered breathing can lead to creation of proinflammatory factors, cytokines, IL-6, TNF- $\alpha(21,46-48)$ and the acute phase protein, $\operatorname{CRP}(20,49,50)$. Inflammation is a part of the pathogenesis and is considered as one of the adverse pregnancy outcomes (51-54). CRP, IL-6 and TNF- $\alpha$ are increased with preeclampsia, (55-58), intrauterine growth restriction (IUGR) $(51,52,59)$, and preterm labor/birth (6063). These factors can lead to preterm birth according to Dudeley, Hosist et al., Menon et al., and Vogel et al., (60-63). According to Bartha et al., Holcberg et al., and Laskowska et al., this factor can lead to Intrauterine Growth Retardation (IUGR) $(51,52,59)$ and according to Afshari et al., Dekker et al., and Hayashi et al., it can lead to preeclampsia (55-58). At the present study, subjective sleep quality is in significant correlation with abortion $(\mathrm{P}=0.000)$.

According to results of the study, there was a significant statistical correlation between abortion and sleep latency $(P=0.000)$, habitual sleep efficiency $(P=0.000)$, and daytime dysfunction $(\mathrm{P}=0.000)$. According to the obtained results from this study, no significant correlation was found between the use of sleeping medication and abortion ( $\mathrm{P}=0.233)$. Mothers claimed that the reason for this issue is fear of complications of the medication on fetus.

This study showed that there is a significant correlation between sleep disorder and abortion $(\mathrm{P}=0.000)$ and in regard with confirmation of this finding, sleep disordered breathing is a factor leading to sleep disorder and AHI is one main factor in field of diagnosing sleep disordered breathing according to PSQI. Lee et al. introduced $\mathrm{AHI}$ as a predicting factor for number of aborted fetus ( $\mathrm{P}$ $=0.002$ ) (36). Moreover, in study done by Louis et al., it was demonstrated that sleep apnea can lead to beginning of spontaneous labor and membrane rupture (37). Numerous studies were done on the effects of sleep on complications of pregnancy and preeclampsia and gestational diabetes while the impact of these factors on abortion was not demonstrated, so this study can be considered as a new work in this field that according to our knowledge in this field that in this study, it was shown for the first time that in the study population is the relationship between sleep disorders during pregnancy and abortion. The disadvantage of this study was to evaluate the relationship is a crosssectional and for further research assessing sleep disorders 
Table 3. The Correlation Between Sleep Quality and Abortion in Studied Groups

\begin{tabular}{|c|c|c|c|c|c|c|c|c|}
\hline Variable & $\begin{array}{c}\text { subjective } \\
\text { Sleep Quality }\end{array}$ & Sleep Latency & Sleep Duration & $\begin{array}{l}\text { Habitual Sleep } \\
\text { Efficiency }\end{array}$ & $\begin{array}{c}\text { Sleep } \\
\text { Disturbances }\end{array}$ & $\begin{array}{l}\text { Use of Sleeping } \\
\text { Medication }\end{array}$ & $\begin{array}{c}\text { Daytime } \\
\text { Dysfunction }\end{array}$ & Total Score \\
\hline P Value & 0.000 & 0.001 & 0.000 & 0.000 & 0.000 & 0.233 & 0.000 & 0.000 \\
\hline
\end{tabular}

abortion utilizes the prospective cohort method is recommended.

\subsection{Conclusion}

According to the obtained results and common complications of pregnancy, it is suggested to pay more attention to sleep health during pregnancy and training women in this field by health caregivers. Moreover, systematic planning in this field of cares during pregnancy by Ministry of Health and announcement of the plans to relevant departments is required.

\section{Acknowledgments}

The article was supported by the Ahvaz University of Medical Science, Khuzestan, Islamic Republic of Iran. The authors acknowledge sincerely from collaboration of research deputy and student research committee of Ahvaz Jundishapur University of Medical Sciences.

\section{References}

1. Poll SoFotSiA. ; 2007. National Sleep Foundation.

2. Shiri H, mazaheri KH, Saidi Abed G, Alavi Majd H. Assessment of amount and type of sleep disorders and sleep hygiene in patients undergoing hemodialysis in the hospital martyr Beheshti University of Medical Sciences. J Nurs Midwifery Martyr Beheshti. 2007;53(11-8).

3. Kryger M, Roth T, Dement W. Principles and practice of sleep medicine. Philadelphia: Lippin Cott; 2005.

4. Memarian R. Apply concepts and theories of nursing. 1 ed. ; 2004. pp. 70-180.

5. Breslau N, Roth T, Rosenthal L, Andreski P. Sleep disturbance and psychiatric disorders: a longitudinal epidemiological study of young adults. Biol Psychiatry. 1996;39(6):411-8. doi: 10.1016/00063223(95)00188-3. [PubMed: 8679786].

6. Wilkie G, Shapiro CM. Sleep deprivation and the postnatal blues. $J$ Psychosom Res. 1992;36(4):309-16. doi:10.1016/0022-3999(92)90067-C. [PubMed: 1593506].

7. Carmona RH. Frontiers of knowledge in sleep and sleep disorders: opportunities for improving health and quality of life. J Clin Sleep Med. 2005;1(1):83-9. [PubMed: 17561618].

8. Phillips B, Ancoli-Israel S. Sleep disorders in the elderly. Sleep Med. 2001;2(2):99-114. doi: 10.1016/S1389-9457(00)00083-6. [PubMed: $11226859]$.

9. Lee KA, Zaffke ME, McEnany G. Parity and sleep patterns during and after pregnancy. Obstet Gynecol. 2000;95(1):14-8. doi: 10.1097/00006250-200001000-00003. [PubMed: 10636494].

10. Okun ML, Coussons-Read ME. Sleep disruption during pregnancy: how does it influence serum cytokines?. J Reprod Immunol. 2007;73(2):158-65. doi:10.1016/j.jri.2006.06.006. [PubMed:17074396].
11. Lee KA. Sleep during pregnancy and postpartum. John Wiley \& Sons; 2006. pp. 629-35.

12. Mindell JA, Jacobson BJ. Sleep disturbances during pregnancy. Obstet Gynecol Neonatal Nurs. 2000;29(6):590-7. doi: 10.1111/j.15526909.2000.tb02072.x. [PubMed: 11110329].

13. Okun ML, Schetter CD, Glynn LM. Poor sleep quality is associated with preterm birth. Sleep. 2011;34(11):1493-8. doi: 10.5665/sleep.1384. [PubMed: 22043120].

14. Baumgartner A, Dietzel M, Saletu B, Wolf R, Campos-Barros A, Graf KJ, et al. Influence of partial sleep deprivation on the secretion of thyrotropin, thyroid hormones, growth hormone, prolactin, luteinizing hormone, follicle stimulating hormone, and estradiol in healthy young women. Psychiatry Res. 1993;48(2):153-78. doi: 10.1016/01651781(93)90039-J. [PubMed: 8416024].

15. Hall JE, Sullivan JP, Richardson GS. Brief wake episodes modulate sleep-inhibited luteinizing hormone secretion in the early follicular phase. J Clin Endocrinol Metab. 2005;90(4):2050-5. doi: 10.1210/jc.2004-2033. [PubMed:15671093].

16. Baker FC, Driver HS. Circadian rhythms, sleep, and the menstrual cycle. Sleep Med. 2007;8(6):613-22. doi: 10.1016/j.sleep.2006.09.011. [PubMed: 17383933].

17. Izci-Balserak B, Pien GW. Sleep-disordered breathing and pregnancy: potential mechanisms and evidence for maternal and fetal morbidity. Curr Opin Pulm Med. 2010;16(6):574-82. doi: 10.1097/MCP.ob013e32833fod55. [PubMed: 20859210].

18. Irwin M, McClintick J, Costlow C, Fortner M, White J, Gillin JC. Partial night sleep deprivation reduces natural killer and cellular immune responses in humans. FASEB J. 1996;10(5):643-53. [PubMed: 8621064].

19. Vgontzas AN, Papanicolaou DA, Bixler EO, Lotsikas A, Zachman K, Kales A, et al. Circadian interleukin-6 secretion and quantity and depth of sleep. J Clin Endocrinol Metab. 1999;84(8):2603-7. doi: 10.1210/jcem.84.8.5894. [PubMed: 10443646].

20. Meier-Ewert HK, Ridker PM, Rifai N, Regan MM, Price NJ, Dinges DF, et al. Effect of sleep loss on C-reactive protein, an inflammatory marker of cardiovascular risk. J Am Coll Cardiol. 2004;43(4):678-83. doi: 10.1016/j.jacc.2003.07.050. [PubMed: 14975482].

21. Irwin MR, Wang M, Campomayor CO, Collado-Hidalgo A, Cole S. Sleep deprivation and activation of morning levels of cellular and genomic markers of inflammation. Arch Intern Med. 2006;166(16):1756-62. doi: 10.1001/archinte.166.16.1756. [PubMed:16983055].

22. Bernardi F, Guolo F, Bortolin T, Petronilho F, Dal-Pizzol F. Oxidative stress and inflammatory markers in normal pregnancy and preeclampsia. J Obstet Gynaecol Res. 2008;34(6):948-51. doi: 10.1111/j.1447-0756.2008.00803.x. [PubMed: 19012691].

23. Cunningham L, Bloom H, Glystrvp V. Williams pregnancy and childbirth. Tehran: Glban; 2015. pp. 820-1357.

24. Jerath R, Barnes VA, Fadel HE. Mechanism of development of preeclampsia linking breathing disorders to endothelial dysfunction. Med Hypotheses. 2009;73(2):163-6. doi: 10.1016/j.mehy.2009.03.007. [PubMed: 19364630].

25. Roberts JM, Hubel CA. Oxidative stress in preeclampsia. Am J Obstet Gynecol. 2004;190(5):1177-8. doi:10.1016/j.ajog.2004.04.001.[PubMed: 15167813].

26. Spiegel K, Leproult R, Van Cauter E. Impact of sleep debt on metabolic and endocrine function. Lancet. 1999;354(9188):1435-9. doi: 10.1016/S0140-6736(99)01376-8. [PubMed: 10543671].

27. The causes of miscarriage [Internet] . 
28. Taype 1 or type 2 diabetes and pregnancy Available from: http://www. cdc.gov/pregnancy/diabetes-types.html.

29. Abortion [Internet].

30. Abortion surveillance-findings and reports [Internet] .

31. Singh S. Hospital admissions resulting from unsafe abortion: estimates from 13 developing countries. Lancet. 2006;368(9550):1887-92. doi:10.1016/S0140-6736(06)69778-X. [PubMed: 17126721].

32. Akhoni M, Behjati Ardakani Z, editors. Necessitate research various aspects of abortion in Iran. Attachment of Journal of Reproduction and Infertility Reproduction and Infertility, abstracts seminar comprehensive study of abortion in Iran. Avicenna Research Institut.

33. Mosavi M, Sadeghzadeh M, Ostadzadeh N. The epidemiologic profile of abortion in women referred to health centers in Qom in 2000.JRes Health Sci. 2001;46.

34. Malek Khosravi SH. The prevalence of abortion and deaths in hospital Kermanshah Moatazedi from 1990 to 2001. Behboud. 2004;9(3):4.

35. Research center for biology and biotechnology reproduction and infertility Jahad Daneshgahi, Society of immunology and allergy of Iran. Second symposium on reproductive Medicine, Immunological factors with recurrent spontaneous abortion 1999.

36. Lee EK, Gutcher ST, Douglass AB. Is sleep-disordered breathing associated with miscarriages? An emerging hypothesis. Med Hypotheses. 2014;82(4):481-5. doi:10.1016/j.mehy.2014.01.031. [PubMed: 24566234].

37. Louis JM, Auckley D, Sokol RJ, Mercer BM. Maternal and neonatal morbidities associated with obstructive sleep apnea complicating pregnancy. Am J Obstet Gynecol. 2010;202(3):261 e1-5. doi: 10.1016/j.ajog.2009.10.867. [PubMed: 20005507].

38. Bourjeily G, Raker CA, Chalhoub M, Miller MA. Pregnancy and fetal outcomes of symptoms of sleep-disordered breathing. Eur Respir J. 2010;36(4):849-55. doi: 10.1183/09031936.00021810. [PubMed: 20525714].

39. Khalil A, Syngelaki A, Maiz N, Zinevich Y, Nicolaides KH. Maternal age and adverse pregnancy outcome: a cohort study. Ultrasound Obstet Gynecol. 2013;42(6):634-43. doi:10.1002/uog.12494. [PubMed: 23630102].

40. Espiritu JR. Aging-related sleep changes. Clin Geriatr Med. 2008;24(1):1-14. doi: 10.1016/j.cger.2007.08.007. [PubMed: 18035227] v.

41. Caughey AB. Poor sleep in pregnancy and mode of delivery. Am J Obstet Gynecol. 2005;193(3 Pt 2):1286. doi: 10.1016/j.ajog.2005.02.122. [PubMed: 16157154] author reply 1286-7.

42. Nasser NA, Al-Habib MF, Baban RS. Body mass index and total serum leptin level in abortion. Iraqi J Med Sci. 2013;11(4):361-7.

43. O'Brien LM. Sleep disruption and adverse pregnancy outcomes. BMC Pregnancy and Childbirth. 2012;2.

44. Donga E, van Dijk M, van Dijk JG, Biermasz NR, Lammers GJ, van Kralingen KW, et al. A single night of partial sleep deprivation induces insulin resistance in multiple metabolic pathways in healthy subjects. J Clin Endocrinol Metab. 2010;95(6):2963-8. doi: 10.1210/jc.20092430. [PubMed: 20371664].

45. Okun ML, Roberts JM, Marsland AL, Hall M. How disturbed sleep may be a risk factor for adverse pregnancy outcomes. Obstet Gynecol Surv. 2009;64(4):273-80. doi: 10.1097/OGX.ob013e318195160e. [PubMed: 19296861].

46. Redwine L, Dang J, Hall M, Irwin M. Disordered sleep, nocturnal cytokines, and immunity in alcoholics. Psychosom Med. 2003;65(1):7585. doi: 10.1097/01.PSY.0000038943.33335.D2. [PubMed: 12554818]

47. Vgontzas AN, Zoumakis E, Bixler EO, Lin HM, Follett H, Kales A, et al. Adverse effects of modest sleep restriction on sleepiness, performance, and inflammatory cytokines. J Clin Endocrinol Metab. 2004;89(5):211926. doi: 10.1210/jc.2003-031562. [PubMed: 15126529].

48. von Kanel R, Dimsdale JE, Ancoli-Israel S, Mills PJ, Patterson TL, McKibbin CL, et al. Poor sleep is associated with higher plasma proinflammatory cytokine interleukin- 6 and procoagulant marker fibrin D-dimer in older caregivers of people with Alzheimer's disease. $J$ Am Geriatr Soc. 2006;54(3):431-7. doi: 10.1111/j.1532-5415.2005.00642.x.
[PubMed: 16551309].

49. Shamsuzzaman AS, Winnicki M, Lanfranchi P, Wolk R, Kara T, Accurso V, et al. Elevated C-reactive protein in patients with obstructive sleep apnea. Circulation. 2002;105(21):2462-4. doi: 10.1161/01.CIR.0000018948.95175.03. [PubMed: 12034649].

50. McDade TW, Hawkley LC, Cacioppo JT. Psychosocial and behavioral predictors of inflammation in middle-aged and older adults: the Chicago health, aging, and social relations study. Psychosom Med. 2006;68(3):376-81. doi: 10.1097/01.psy.0000221371.43607.64. [PubMed: $16738067]$.

51. Holcberg G, Huleihel M, Sapir O, Katz M, Tsadkin M, Furman B, et al. Increased production of tumor necrosis factor-alpha TNF-alpha by IUGR human placentae. Eur J Obstet Gynecol Reprod Biol. 2001;94(1):69-72. doi:10.1016/S0301-2115(00)00321-3. [PubMed: 11134828].

52. Bartha JL, Romero-Carmona R, Comino-Delgado R. Inflammatory cytokines in intrauterine growth retardation. Acta Obstet Gynecol Scand. 2003;82(12):1099-102. doi: 10.1046/j.1600-0412.2003.00259.x. [PubMed: 14616253].

53. Freeman DJ, McManus F, Brown EA, Cherry L, Norrie J, Ramsay JE, et al. Short- and long-term changes in plasma inflammatory markers associated with preeclampsia. Hypertension. 2004;44(5):708-14. doi: 10.1161/01.HYP.0000143849.67254.ca. [PubMed: 15452036].

54. Romero R, Espinoza J, Goncalves LF, Kusanovic JP, Friel LA, Nien JK. Inflammation in preterm and term labour and delivery. Semin Fetal Neonatal Med. 2006;11(5):317-26. doi: 10.1016/j.siny.2006.05.001. [PubMed: 16839830].

55. Dekker GA, Sibai BM. The immunology of preeclampsia. Semin Perinatol. 1999;23(1):24-33. doi:10.1016/S0146-0005(99)80057-3. [PubMed 10102168].

56. Afshari JT, Ghomian N, Shameli A, Shakeri MT, Fahmidehkar MA, Mahajer E, et al. Determination of Interleukin-6 and Tumor Necrosis Factor-alpha concentrations in Iranian-Khorasanian patients with preeclampsia. BMC Pregnancy Childbirth. 2005;5:14. doi: 10.1186/14712393-5-14. [PubMed: 16259641].

57. Hayashi M, Ueda Y, Ohkura T, Inaba N. Interleukin- 6 concentrations in the placenta and blood in normal pregnancies and preeclampsia. Horm Metab Res. 2005;37(7):419-24. doi: 10.1055/s-2005-870231. [PubMed: 16034713].

58. Hayashi M, Ueda Y, Yamaguchi T, Sohma R, Shibazaki M, Ohkura T, et al. Tumor necrosis factor-alpha in the placenta is not elevated in preeclamptic patients despite its elevation in peripheral blood. Am J Reprod Immunol. 2005;53(3):113-9. doi: 10.1111/j.1600-0897.2005.00253.x. [PubMed: 15727564].

59. Laskowska M, Leszczynska-Gorzelak B, Laskowska K, Oleszczuk J Evaluation of maternal and umbilical serum TNFalpha levels in preeclamptic pregnancies in the intrauterine normal and growthrestricted fetus. J Matern Fetal Neonatal Med. 2006;19(6):347-51. doi: 10.1080/14767050600637937. [PubMed: 16801311].

60. Dudley D. Cytokines in preterm and term parturition. New York: John Wiley \& Sons; 2000.

61. Holst RM, Mattsby-Baltzer I, Wennerholm UB, Hagberg H, Jacobsson B. Interleukin- 6 and interleukin-8 in cervical fluid in a population of Swedish women in preterm labor: relationship to microbial invasion of the amniotic fluid, intra-amniotic inflammation, and preterm delivery. Acta Obstet Gynecol Scand. 2005;84(6):551-7. doi: 10.1111/j.00016349.2005.00708.x. [PubMed: 15901266].

62. Vogel I, Thorsen P, Curry A, Sandager P, Uldbjerg N. Biomarkers for the prediction of preterm delivery. Acta Obstet Gynecol Scand. 2005;84(6):516-25. doi: 10.1111/j.0001-6349.2005.00771.x. [PubMed: 15901257].

63. Menon R, Merialdi M, Lombardi SJ, Fortunato SJ. Differences in the placental membrane cytokine response: a possible explanation for the racial disparity in preterm birth. Am J Reprod Immunol. 2006;56(2):1128. doi: 10.1111/j.1600-0897.2006.00394.x. [PubMed: 16836613]. 